\title{
REVIEW
}

\section{Emergency analgesia in the paediatric population. Part I Current practice and perspectives}

\section{S C Maurice, J J O'Donnell, T F Beattie}

Emerg Med J 2002;19:4-7

Children frequently present to the accident and emergency (A\&E) department in pain. Most presentations are acute, but children with pain of longer duration also present. Children also often undergo painful procedures in A\&E in the process of diagnosis or treatment. These papers review recent literature to examine factors involved in the provision of emergency analgesia in the paediatric population. This will include a discussion of current practice and make recommendations for future management of children's pain and anxiety in the A\&E department. Part I: Current practice and perspectives. Part II: Pharmacological methods of paediatric analgesia. Part III: Non-pharmacological methods of pain control and anxiolysis. Part IV: Paediatric sedation in accident and emergency.

See end of article for authors' affiliations

................

Correspondence to: Dr S C Maurice, c/o Accident and Emergency

Department, Wythenshawe Hospital, Southmoor Road, Wythenshawe, Manchester M23 9LT, UK;

sue.maurice@

gw.smuht.nwest.nhs.uk

Accepted for publication 11 May 2001

\section{CURRENT PRACTICE AND PERSPECTIVES}

"Paediatric patients seldom need medication for the relief of pain. They tolerate discomfort well." L I Swafford, D Allen, 1968.'

As recently as a decade ago, children and especially neonates were felt to have less capacity than adults to feel and remember pain and therefore to require less analgesia. ${ }^{2-6}$ This has led to inadequate treatment of children in pain and unnecessary suffering in a particularly vulnerable group of patients - sick or injured children and infants. ${ }^{7-10}$

There seems to be two main reasons for the belief that children do not experience pain to the same degree as adults. Firstly, it was thought that children were less able to feel pain as their nervous system is immature and incompletely myelinated. ${ }^{11}$ Secondly, it has been argued that as young children have no experience of pain, they cannot understand or perceive nociception as adults do.

Pain occurs after stimulation of specific nerve endings or nociceptors lying in the skin and musculoskeletal tissues. There are two types of afferent nociceptive fibres; fast A fibres and slow $\mathrm{C}$ fibres. Thin myelinated fast A delta fibres have a conduction velocity of $10-20 \mathrm{~m} / \mathrm{s}$ and result in immediate sharp, well localised pain. Unmyelinated $C$ fibres have a slower conduction velocity of $1 \mathrm{~m} / \mathrm{s}$ and result in dull aching, diffuse pain. Both A delta and C fibres enter the spinal cord via the dorsal root, terminating in the dorsal horn. The ascending fibres of the spinothalamic tract transmit the impulses to the cerebral cortex mainly by the neurotransmitter peptide, substance $\mathrm{P}^{12}$

Pain transmission can be modified at several points. At a spinal level large diameter A beta fibres transmit impulses from low threshold impulses sensitive to touch, pressure and vibration, which inhibit nociceptive transmission. This explains the analgesic effect of massage, transcutaneous nerve stimulation and perhaps even the concept of "rubbing it better". Pain can also be modified centrally by descending inhibitory fibres, which may explain why people in intense emotional situations, such as a fight, do not feel pain. The modification of pain transmission by inhibitory neurones is the gate theory of pain. ${ }^{13-16}$

There is now clear evidence that the cutaneous receptors, neural pathways, neurotransmitters and the cortical senses required for pain perception are present by mid-gestation and are fully organised in infancy. ${ }^{17-19}$ The nociceptive nerve tracts in the spinal cord and central nervous system undergo myelination during the second and third trimesters of gestation. In adults, the nociceptive impulses in the peripheral nerves are carried through unmyelinated C fibres and thinly myelinated A delta fibres. It would appear that complete myelination is not necessary for pain perception and therefore newborn babies who have partial myelination are capable of experiencing pain. ${ }^{19}$ Although infant neurones are incompletely myelinated, this will not result in lack of function, but only in slightly slower conduction. In infants slower conduction velocity is also compensated for by shorter interneuronal distances. ${ }^{20}$ In 1987 LeDez and Lerman showed that not only did premature neonates respond to painful stimuli, but that use of anaesthetic agents blunted this response just as in adults. ${ }^{21}$

The International Association for the Study of Pain has defined pain as "an unpleasant sensory and emotional experience associated with actual or potential tissue damage, or described in terms of such damage. Pain is always subjective. Each individual learns the application of the word through experiences related to injury in early life."22

It has been argued that children with no prior experience of pain will not perceive a nociceptive stimulus to the same degree as adults, and that when the discomfort stops the experience stops with no lasting psychological sequelae. This experiential theory of limited pain perception in children has been disproved by the large body of evidence, which demonstrates that children and even preterm infants can mount behavioural and physiological responses to pain. ${ }^{2}{ }^{19}$ Children and infants 
have been shown to respond to a painful stimulus with changes in heart rate, blood pressure, palm sweating, facial expressions and crying, as well as complex behavioural changes in sleep cycles, REM sleep and feeding patterns. Work by Anand et al demonstrated that infants undergoing surgery with little or no analgesia mounted a significant stress response with increased release of catecholamines, growth hormone, glucagon and corticosteroids, and insulin suppression, resulting in prolonged hyperglycaemia, and increases in blood lactate and ketones. ${ }^{23}{ }^{24}$

Infants who received potent analgesia have been shown to have significantly fewer complications postoperatively. ${ }^{25}$ There is, therefore, comprehensive evidence that infants and children can and do perceive pain ${ }^{21926}$ and should not be denied pain relief. It is our role as medical and nursing staff to recognise the emergency situations in which a child may be in pain; to quantify the pain and treat it appropriately.

Having established that children experience pain, we need to find out if we provide adequate analgesia to the children attending our accident and emergency (A\&E) departments.

\section{EMERGENCY PROVISION OF ANALGESIA IN THE PAEDIATRIC POPULATION}

Recent literature has repeatedly demonstrated the provision of analgesia to be suboptimal in the paediatric population generally. Southall et al showed that of 181 invasive procedures performed on children receiving intensive care, only 50 (28\%) received additional analgesia or sedation and during 36 of these procedures the child grimaced or cried. ${ }^{9}$ Beyer et al found that following cardiac surgery, children received only one tenth of the total doses of analgesia administered to adults, and $10 \%$ received no analgesia at all. ${ }^{27}$ Numerous other examples in the literature confirm the widespread inappropriate attitude of many medical staff to paediatric pain management. ${ }^{28-30}$ There are many situations in the A\&E department in which children require analgesia, either to relieve the pain of their presenting condition, or to reduce the discomfort of painful procedures such as venesection and cannula insertion.

Despite pain being one of the commonest presenting complaints of children attending $\mathrm{A} \& \mathrm{E}$, it is managed very poorly. ${ }^{31-33}$ When surveying the notes of 90 children and 90 adults with similar diagnoses (appendicitis, fractured femur, burns), Schechter et al found that adults received twice the number of opioid doses that children did, with young children being the least likely to receive opioids. ${ }^{34}$

Friedland and Kulick reviewed 99 children with acute fractures assumed to be painful and found that only 53\% received analgesia. Children with head injuries received analgesia less frequently than those with an isolated fracture despite all head injuries being minor (GCS 14-15). No significant clinical difference was detected between the analgesic and nonanalgesic group. ${ }^{8}$

Selbst and Clark in 1990 performed a retrospective review to see if children received similar analgesic treatment to adults when presenting with similar acutely painful conditions, such as sickle cell crises, long bone fractures and burns. Sixty per cent of adults with painful conditions received no analgesia at all, but children were much less likely to receive analgesia than adults $(28 \%, \mathrm{p}=0.001)$. Considering children specifically, those less than 2 years old were much less likely than older children to receive any medication for pain (17\% $\vee 38 \%$, $\mathrm{p}<0.01)$. Children were also far less likely to be discharged home with analgesia than adults. ${ }^{33}$

A recent postal survey of the South $\&$ West region of England showed that only $20 \%$ of A\&E departments have a policy for pain management in children, only $35 \%$ routinely assess and record children's pain scores and only $50 \%$ give formal training in pain management to medical and nursing staff. ${ }^{7}$

In order to improve analgesia provision in the paediatric population in A\&E, the next step is to explore the reasons for this bad practice.

\section{WHY IS PAEDIATRIC ANALGESIA PROVISION IN A\&E INADEQUATE?}

A number of factors contribute to the undertreatment of children's pain in A\&E and include poor communication between patient, parent and staff, poor objective pain assessment and staff inexperience at prescribing and administering analgesia.

\section{Communication problems}

Children are less articulate than adults in expressing their experience of pain for several reasons. Young children who are pre-verbal will only be able to express their needs and feelings by crying so physicians may not be aware that the crying is due to pain. An adult indicating that he or she is in pain is likely to get a response but a young child who is crying is easier to ignore. ${ }^{35}$ We may perceive it to be a normal reaction for a child to cry in the A\&E department. When unwell or in pain children often revert to behaviour appropriate for a younger child and may revert to the pre-verbal state. Some children become introverted and silent in the frightening atmosphere of the A\&E department, being reluctant to admit they are in pain for fear of receiving an injection or some other unpleasant treatment. A child may even have been taught that it is cowardly or childish to admit to pain, and that to suffer pain is character building; "no pain, no gain". Victims of abuse may deny pain for fear of further assault.

Five main stressors have been cited that children associate with hospitalisation. ${ }^{36}$

These are fear of

- physical harm or bodily injury in the form of pain, mutilation or death

- Separation from parents

- Strange environment and procedures

- Loss of control, autonomy and competence

- Uncertainty about expected acceptable behaviour

Although this work was not specific to A\&E it gives valuable insight to the experience of children attending A\&E departments.

Children may attend hospital with preconceived ideas learnt from parents or other children. Parents may unintentionally condition their children into believing a hospital is a place to be feared where painful procedures are performed, rather than a place where pain and illness is relieved and "made better". This may be through the parents' own fear of hospitals or their anxiety and sometimes guilt at their own child suffering an injury or illness. A child seeing their parent upset or distressed by the hospital environment will rapidly feel insecure and frightened themselves. Parents may even use the threat of hospitals as punishment, treating the doctor as a bogeyman. All these ideas will act to augment rather than diminish the child's pain experience.

Children are unable to withdraw their consent for procedures and hospital staff may persuade parents that it is in the child's interest to use physical restraint for unpleasant procedures. It is unthinkable to imagine holding an adult down to perform a painful or unpleasant procedure without sedation or analgesia and yet this happens routinely with children. Possible reasons for this are staff shortages, lack of time and sometimes even laziness. With the pressures of busy departments and long waiting times we may not take the time to give the child a full explanation of proposed procedures in order to allow them to gain the confidence to cooperate with us. Also children are unlikely to sue or press charges if they are held down for a procedure against their will. Very rarely it may be in the child's interest to use restraint for a short procedure, for example, to avoid a general anaesthetic and overnight hospital stay. This should be a last resort and effective analgesia, sedation and constant reassurance should always be provided both during and after the procedure. 


\section{Poor pain assessment}

Objective pain assessment in children is notoriously difficult, partly because of their difficulty in communicating pain. Children cannot be relied upon to report their pain accurately and a simple reproducible objective pain assessment tool is required.

The lack of a universal assessment technique fosters undertreatment of children's pain. Research in this area is limited as there is no solid outcome measure. As a result studies are difficult to replicate and are not easily generalised to the paediatric population attending $\mathrm{A} \& \mathrm{E}$.

Pain assessment is rarely made in children and, if performed, often underestimates a child's pain. ${ }^{37}$ Despite the difficulties, it is the duty of A\&E staff to maintain a high index of suspicion in order to recognise, quantify and treat a child's pain appropriately.

Various pain tools using verbal, behavioural or physiological parameters have been devised, some of which will be described below. As more easily performed assessment techniques are developed, clinical care will improve and reliable research will be possible.

Once assessment has been made and analgesia provided, pain levels should be reassessed periodically to determine the continuing adequacy of pain relief and the need for further analgesia.

\section{Staff inexperience}

The medical school curriculum and training of junior doctors does not prepare staff adequately to provide analgesia to children, ${ }^{38}$ and pain management is rarely taught in A\&E. ${ }^{7}$ This is especially relevant when treating children, as factors such as poor communication and difficulty in pain assessment complicate the situation.

Junior A\&E doctors are often unfamiliar with the analgesic agents suitable for paediatric use, or with the local anaesthetic techniques and non-pharmacological methods of pain relief available. A recent study by Sandhu et al shows that many SHOs in A\&E lack confidence when prescribing opioids in both adults and children and few would titrate analgesia against the patient's response..$^{39}$ It has been speculated in the past that because of hepatic immaturity the half life of opioids is increased in children, who will thus need less frequent dosing. This may lead to opioids being withheld or used in insufficient doses and by inappropriate routes for fear of side effects such as respiratory depression and hypotension. Although infants less than a month old have a prolonged half life and decreased clearance of morphine, children over a month old have essentially adult-like morphine pharmacokinetics. ${ }^{40}$

Some doctors feel that introducing opioids at an early age can lead to addiction. Physical addiction is a physiological state that will occur if an individual receives opioids for seven days or more, so will not occur from A\&E administration. If a child's condition requires opioid use for several days, gradual withdrawal will avoid withdrawal symptoms. As defined by Jaffe, in the most frequently used definition, ${ }^{41}$ addiction "is a behavioural pattern of drug use characterized by overwhelming involvement with the use of the drug, the securing of its supply, and a high tendency towards relapse after its withdrawal". Studies in adults suggest that addiction developing after hospital use of opioids for acute pain is extraordinarily rare. ${ }^{42}$ Although there are no studies for children, the results are likely to be comparable. Despite this, $39 \%$ of paediatricians, family practitioners and surgeons admitted to concern about addiction when prescribing opioids to children. ${ }^{43}$

Fear of masking physical signs may also lead to doctors denying patients analgesia. Despite studies demonstrating that reducing patients' pain does not cloud diagnostic skills and may even facilitate assessment, analgesia is often withheld. ${ }^{44}$ Rather than causing complications and side effects, children have been shown to have lower complication rates postoperatively when given appropriate analgesia. ${ }^{25}$
Safe analgesic agents are available for children of all ages and we must train our juniors to be safe and confident in their use in the emergency environment.

\section{PAIN ASSESSMENT}

To treat children's pain effectively, we must become familiar with the pain assessment tools available to assess and quantify pain. These include:

\section{Observation of behaviour}

A child's behaviour such as crying, holding an injured body part protectively, and verbalisation of pain can be recognised. The parent's knowledge of the child's usual pain behaviour is useful.

\section{Inference}

The type of injury sustained or illness presented can give clues to the degree of pain the child is experiencing.

\section{Objective pain tools}

Objective assessment of a child's pain allows selection of appropriate analgesia. Subsequent re-assessment determines the adequacy of analgesia and the need for further pain relief. ${ }^{45}$ Assessment should be performed as soon as possible after the child arrives at the A\&E department, preferably as part of the triage procedure. The degree of pain will influence the triage group into which the child is placed. Pain assessment should be made on all children attending A\&E.

The use of pain tools has largely been restricted to research in the past, and there is no evidence that their use improves patient outcome. They take time and patience to explain to the patient and generate increased paper work. However, establishing the routine use of these scales is likely to help standardise and improve pain management in A\&E. ${ }^{46}$ Various pain tools have been devised including visual analogue scales, numerical scales and "Happy face/Sad face" scales. ${ }^{37}$ Children over 4 years can usually understand and cooperate with these types of pain tools. It is worthwhile choosing one type of scale and becoming familiar and consistent with its use, rather than swapping between different scales.

The visual analogue scale consists of a straight line with verbal anchors of "no pain" and "very severe pain" at each end. The child picks the point along the line that describes the degree of pain they feel. The visual analogue scale can also have numerical anchors in which the child chooses a number from 1 to 10 , with 1 signifying "no pain" up to 10 signifying "unbearable pain, or the worst pain imaginable.".37 47

The Happy face/Sad face tool consists of a row of faces ranging from a happy, smiling face to an unhappy, crying face. The child picks the face that best describes their pain. ${ }^{48} 49$

For children younger than 4 or 5 years who cannot understand the pain tools described above, a physiological measure of their pain can be made, using indicators such as increased pulse rate, raised blood pressure, sweating, pallor and dilated pupils.

Alternatively, pain can be assessed in the younger child with behavioural scales such as the CHEOPS (Children's Hospital of Eastern Ontario Pain Scale) or the system developed by Grunau and Craig, which assesses infant pain by crying or facial grimacing. ${ }^{50}{ }^{51}$ Both these methods carry the disadvantage that there are many confounding factors that cause physiological and behavioural changes apart from pain. ${ }^{52}$

If the child is too distressed to communicate their pain level adequately, the triage nurse or doctor should make a quantitative estimate of their pain level with the aid of the child's parent or carer. The pain score and time should be recorded and repeated periodically to assess the efficacy of analgesia and the need for further pain relief.

Children found to be in pain should be prescribed analgesia immediately and undergo medical assessment to elicit the 
underlying cause of their pain. Ideally nursing staff should have the authority to prescribe simple analgesia at the triage station.

\section{SUMMARY}

There is indisputable evidence that even very young children experience pain. Children's pain is universally undertreated in our A\&E departments. The reasons for this are poor communication between patient, parent and staff, inadequate pain recognition and assessment and poor understanding of analgesic drugs and techniques available for children.

A child's experience of pain is not linearly related to the amount of tissue damage present. It is a composite of the nociceptive stimulation due to tissue damage combined with many modifying factors which may magnify or diminish the pain. ${ }^{10}$

Therefore, to tackle the undertreatment of paediatric pain in A\&E we must approach the problem from several directions:

\section{Pain recognition and assessment}

2 Education of A\&E staff regarding pharmacology of various analgesics and their use in children

3 Improving the A\&E department to provide a child friendly, non-threatening environment

4 Appropriate use of a wide spectrum of pain relieving methods including analgesic drugs, local anaesthesia, and nonpharmacological methods of pain relief.

\section{ACKNOWLEDGMENENTS}

Contributors: SCM undertook the initial literature review and completed the first draft of the paper. JJO'D contributed to the literature review, discussed the core ideas and edited the paper. TFB developed the original idea, led discussions on the topics to be studied and co-ordinated the series of papers. TFB is the guarantor for the paper.

\section{Authors' affiliations}

S C Maurice, Accident and Emergency Department, Wythenshawe Hospital, Southmoor Road, Wythenshawe, Manchester M23 9LT, UK J J O'Donnell, T F Beattie, Accident and Emergency Department, Royal Hospital for Sick Children, Sciennes Road, Edinburgh EH9 1LF, UK

\section{REFERENCES}

1 Swafford LI, Allan D. Pain relief in the pediatric patient. Med Clin N Am 1968;52:131-6.

2 Aynsley-Green A, Ward Platt MP. Pain. In: Recent advances in paediatrics no 11. Edinburgh: Churchill Livingstone, 1993.

3 Wellington N, Rieder $M$. Attitudes and practices regarding analgesia for newborn circumcision. Pediatrics 1993;92:541-3.

4 Bhatt-Mehta V, Rosen DA. Management of acute pain in children. Clin Pharmacol 1991;10:667-85.

5 Burrows FA, Berde CA. Optimal pain relief in infants and children. BM 1993;307:815-16

6 Purcell-Jones G, Dormon F, Sumner E. Paediatric anaesthetist's perceptions of neonatal and infant pain. Pain 1988;33:181-7.

7 Simpson N, Finlay F. Acute pain management for children in A\&E. [Letter]. J Accid Emerg Med 1997;14:58.

8 Friedland LR, Kulick RM. Emergency department analgesic use in pediatric trauma victims with fractures. Ann Emerg Med 1994:23:203-7.

9 Southall DP, Cronin BC, Hartmann $\mathrm{H}$, et al. Invasive procedures in children receiving intensive care. BM 1993;306:1512-13.

10 Schechter NL. The under treatment of pain in children: an overview. Pediatr Clin N Am 1989:36:781-94.

11 McGraw MB. Neural maturation as exemplified in the changing reactions of the infant to pin prick. Child Dev 1941;9:31

12 Ganong WF. Review of medical physiology. 16th edn. San Francisco: Appleton and Lange, 1993.

13 Melzack R, Wall PD. Pain mechanisms, a new theory. Science 1965;150:971-9.

14 Melzack R, Wall PD. Pain mechanisms, a new theory. Science 1965;179:1011-14

15 Illingworth KA, Simpson KH. Anaesthesia and analgesia in emergency medicine. Oxford: Oxford University Press, 1998.

16 Skinner D, Swain A, Peyton R, et al, eds. Cambridge textbook of A\&E medicine. Cambridge: Cambridge University Press 1997.
17 Derbyshire SWG, Furedi A. Do fetuses feel pain? BM 1996; 313:795-9

18 Fitzgerald $\boldsymbol{M}$. The developmental neurobiology of pain. Proceedings of the Vlth World Congress on Pain. Amsterdam: Elsevier Science, 1991:253-61.

19 Anand KJS, Hickey PR. Pain in the foetus and neonate or pain and its effects in the human neonate and fetus. NEJM 1987;317:1321-9.

20 Fitzgerald $\mathbf{M}$. Development of pain mechanisms. Br Med Bull 1991;47:667-75

21 LeDez KM, Lerman J. The minimum alveolar concentration (MAC) of isoflurane in preterm neonates. Anesthesiology 1987;67:301-7.

22 Merskey H, Albe-Fessard DG, Bonica JJ. Pain terms: A list with definitions and notes on usage: recommended by the IASP subcommittee on taxonomy. Pain 1979;7:249-52.

23 Anand KJS, Sippell WG, Aynsley-Green A. Randomised trial of fentanyl anaesthesia in preterm neonates undergoing surgery; effects on the stress response. Lancet 1987; i:243-8.

24 Anand KJS, Hansen DD, Hickey PR. Hormonal-metabolic stress response in neonates undergoing cardiac surgery. Anesthesiology 1990;73:661-70.

25 Anand KJS, Carr DB. The neuroanatomy, neurophysiology and neurochemistry of pain, stress and analgesia in newborns and children. Pediatr Clin N Am 1989;36:795-827.

26 Mahan KT, Strelecky DC. Recent concepts in understanding a child's pain. Journal of the American Pediatric Medical Association 1991;81:5:231-42.

27 Beyer J, DeGood DE, Ashley LC, et al. Patterns of post-operative analgesic use with adults and children following cardiac surgery. Pain $1983 ; 17: 71-81$

28 McGrath PJ, Unruh AM. Pain in children and adolescents. Pain research and clinical management. Vol 1. Amsterdam: Elsevier, 1987.

29 Ross DM, Ross SA. Childhood pain; current issues, research and management.. Baltimore: Urban and Schwarzenberg, 1988.

30 Bush JP, Harkins SW. Conceptual foundations: pain and child development. In: Children in pain: clinical and research issues from a developmental perspective. New York: Springer-Verlag, 1991:1-30.

31 Selbst SM. Analgesia in children. Why is it underused in emergency departments? Drug Safety 1992;7: 8-13.

32 Anon. Managing acute pain in children. Drug Ther Bull 1995;33:41-4

33 Selbst SM, Clark M. Analgesic use in the emergency department Ann Emerg Med 1990;19:1010-13.

34 Schechter NL, Allen DA, Hanson K. Status of pediatric pain control: A comparison of hospital analgesic usage in children and adults. Pediatrcs 1986;77:11-15

35 Selbst SM, Henretig FM. The treatment of pain in the emergency department. Pediatr Clin N Am 1989;36:965-78.

36 Visitainer MA, Wolfer JA. Psychological preparation for surgical pediatric patients: the effect on children's and parent's stress responses and adjustment. Pediatrics 1975;56:187-202

37 Ducharme J. Emergency pain management: A Canadian Association of Emergency Physicians (CAEP) Consensus Document. J Emerg Med 1994; 12:855-66

38 Reichl M, Bodiwala GG. Use of analgesia in severe pain in the accident and emergency department. Arch Emerg Med 1987;4:25-31.

39 Sandhu S, Driscoll P, Nancarrow J, et al. Analgesia in the accident and emergency department: Do SHOs have the knowledge to provide optimal analgesia. J Accid Emerg Med 1998;15:147-50.

40 Yaster M, Deshpande JR. Management of pediatric pain with opioid analgesics. J Pediatrics 1988;113:421-9.

41 Jaffe J. Drug addiction and drug abuse. In: Gillman AG, Goodman LS, Roll TW, et al. Pharmacological basis of therapeutics. New York: Macmillan, 1985

42 Porter J, Jick $\mathrm{H}$. Addiction rare in patients treated with narcotics. [Letter] NEJM 1980;302:123.

43 Schechter NL, Allen DA. Physicians' attitudes toward pain in children. J Dev Behav Pediatr 1986;7:350-4.

44 Attard AR, Corlett M, Kidner NJ, et al. Safety of early pain relief for acute abdominal pain. BM 1992;305:554-6.

45 McGrath PA. Pain in the pediatric patient: practical aspects of assessment Pediatr Ann 1995;24:126-33, 137-8.

46 Govier I. Assessment of pain in the A\&E department. Nursing Times 1992;88:44-59.

47 Jadad AR, McQuay HJ. The measurement of pain. In: Outcome measures in orthopaedics. London: Butterworth Heinemann, 1993.

48 Bieri D, Reeve RA, Champion GD, et al. The faces pain scale for the self-assessment of the severity of pain experienced by children: development, initial validation, and preliminary investigations for ratio scale properties. Pain 1990;41:139-50.

49 Wong DL, Whalley LF. Nursing care of children and infants. 4th edn. St Louis: CV Mosby, 1991

50 McGrath PJ, Johnson G, Goodman JT, et al. The CHEOPS: A behavioral scale to measure post-operative pain in children. In: Fields HL, Dubner R Cervero F, eds. Advances in pain research and therapy: proceedings of $4^{\text {th }}$ world congress on pain, vol 9. New York: Raven Press, 1985:395-402.

51 Grunau RVE, Craig KD. Pain expression in neonates; facial expression and cry. Pain 1987;28:395-410.

52 Benini $F$, Johnston C, Faucher D, et al. Topical anesthesia during circumcision in newborn infants. JAMA 1993;270:850-3. 